\title{
Antimicrobial Composites and Coatings Based On Them
}

\author{
Kh Barbakadze', G Lekishvili², B Arziani² and N Lekishvili* \\ ${ }^{1}$ Department of Chemistry, Institute of Inorganic-Organic Hybrid Compounds and Non-traditional Materials, Georgia \\ ${ }^{2}$ Tbilisi State Medical University Tbilisi, Georgia \\ *Corresponding author: N Lekishvili, Faculty of Exact and Natural Sciences, Tbilisi State University, Tbilisi, Georgia
}

Submission: 眥January 02, 2018; Published: 海 May 24, 2018

Abbreviations: DSC: Differential Scanning Calorimetric; TGA: Thermo Gravimetric Analysis Method

\section{Introduction}

The effects of pathogenic microorganisms constitute global hazards for humanity and the environment. These micro $\urcorner$ organisms appear in natural systems and form complicated aggregates on the surfaces of various natural and synthetic polymers resulting in irreversible deterioration and non-controlled biodegradation that cause significant economic losses to industry and pose serious threats to cultural heritage (historic monuments, archeological patterns, museum exhibits, etc.) as well [1,2].

An important option in mitigation biodegradation is in formation of polymer based hybrid materials, taking advantage of the best properties of each component, decreasing or eliminating their drawbacks, and achieving synergic effects. Low scratch and wear resistance and also environmental degradation have hindered many important applications and long term performance of polymer materials [3,4]. Thus, it is essential to achieve prolonged maintaining of their physical and mechanical properties (isothermal aging stability, strength, tribological characteristics, etc.) in operational conditions. Improved features which affect on the operational characteristics of the hybrid materials will reduce the risk of bio-damaging caused by bio destructors and effectively provides inhibition of growth of harmful microorganisms on materials surfaces and allow their applications as functional coatings, adhesives, membranes, optics, fuel and solar cells, sensors, medical products and materials, etc. [4].

The main concept of the following research consisted in creation of bioactive hybrid materials against wide spectrum of biodestructors. For cre $\neg$ a $\neg$ tion of antimikrobial compo $\urcorner$ si $\neg \neg$ tes as a base of poly $\neg$ meric matrix of inor-ga $\neg$ nic-organic hybrid mate $\neg$ rials polyurethanes and organic polyepoxide were used. Silicon-organic oligomers with functional groups at silicon atoms act as plasticizers and modifiers and improve elasticity, thermal stability, of polymer coatings. They also improve forming homogeneous films and hydrophobicity of the obtained composites [5].

As a bio $a$ ac $\neg$ ti $\neg$ ve component adamantan ferrocene coordination complexes of biogenic metals ( $\mathrm{Fe}, \mathrm{Co}, \mathrm{Ni}$ ) were chosen [6]. Thermophysical properties of the obtained polymer composites and corresponding antimicrobial coatings were studied by the differential scanning calorimetric (DSC) and thermo gravimetric (TGA) analysis methods.

All materials studied are amorphous, melting transitions are not visible. Almost all hybrids have glass transition regions beginning in the range more than $50 \mathrm{oC}$. This is important for the use of coatings for protection of museum exhibits since the optical clarity at room temperature and above is assured. Thermal stability of the modified hybrids increases with respect to the pure polymeric matrices. Herewith resistance to thermal degradation is enhanced and weight loss is shifted to higher temperatures as the amount of poly organo $\neg$ siloxanes increase and further is improved by addition of bioactive components.

Tribological properties of hybrids are related to their composition. The sliding wear (SWD) of the samples was determined by multiple scratching along the same groove at a constant force using a micro scratch tester. The influence of nature and structure of bioactive compounds, receptor and technological factors of their preparation on the properties of targeted multifunctional hybrid composites and materials based on them have been studied.

The modification mainly causes gradual decrease of sliding wear with respect to pure polymers, improvement of viscoelastic recovery (75-90\%), lowering of dynamic friction and also increasing of hydrophobicity. Progressive scratch testing with linearly increased load $(1.0 \mathrm{~N}-30.0 \mathrm{~N})$ was performed to study scratch 
resistance of researched materials. As was shown, modification does improve scratch resistance depending on the modifier type and quantity with respect to pure polymers.

The study of surface morphology of obtained composites and coatings (by SEM) confirmed that by modification wear resistance of polymer composites is increased. Thus, it is possible to achieve both lower friction and a higher scratch resistance with definite concentration of modifiers.

New biologically active - antimicrobial, fungi static/fungicidal (antimycotic) polymer materials of multi-vectorial and directional action based on polyurethane and epoxy matrix for human, cultural heritage and environmental protection developed. Created antimicrobial polymer materials show improved mechanical, tribological and thermophysical properties and provide the prolonged exploitation of the protected materials and wares. This on the other hand will economize material resources. Herewith elimination of unfavorable factors which affect on the operational characteristics and surface morphology of the hybrid materials reduce the risk of bio-damaging caused by biodestructors and effectively provides inhibition of growth of harmful microorganisms on materials surfaces. The obtained antimicrobial coatings have also real perspective for their use for protection synthetic and natural polymeric materials from bio-deterioration and noncontrolled biodegradation.

\section{References}

1. JD Gu (2003) Microbiological deterioration and degradation of synthetic polymeric materials: recent research advances. Internat Biodeterior \& Biodegrade 52(2): 69-91.

2. European Commission (2009) Preserving our heritage, improving our environment, pp. 248.

3. Y Yamamoto, $\mathrm{T}$ Takashima (2002) Friction and wear of water lubricated PEEK and PPS sliding contacts Wear. 253(7): 820-826.

4. R Gómez Romero, C Sanchez (2004) Hybrid materials functional applications: An introduction in Functional hybrid materials. Wiley VCH Weinheim/ Bergstrasse, Germany, p. 1-14.

5. B Oktay, N Kayaman Apohan (2013) Polydimethylsiloxane (PDMS) based antibacterial organic-inorganic hybrid coatings. J. Coat Technol Res 10(6): 785-798.

6. Kh Barbakadze, G Lekishvili (2014) Novel ferrocene derivatives with polycyclic spatial groups synthesis, study and application. Asian J Chem 26 (5): 1315-1317.
Creative Commons Attribution 4.0

International License

For possible submissions Click Here

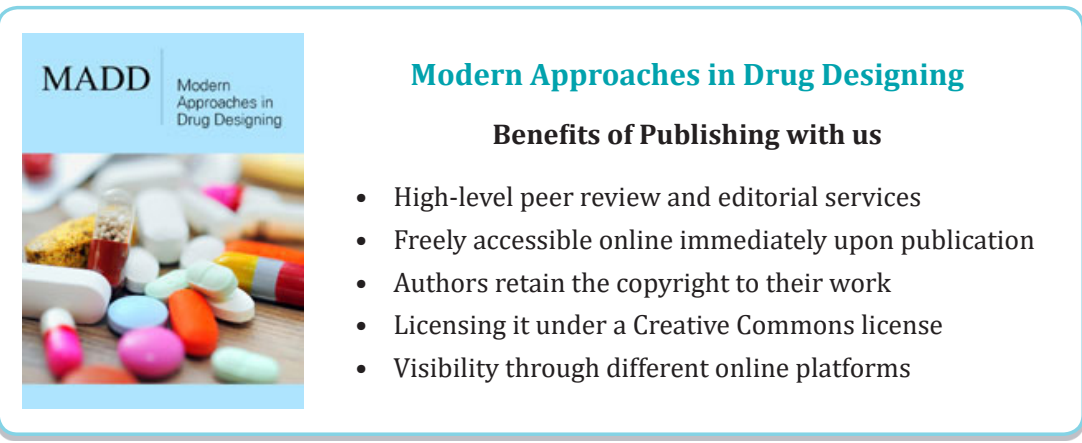

